\title{
A Systemic Review on Single-Port and Multiport Laparoscopic Hernioplasty
}

\author{
Bipin Thomas Prasad ${ }^{1} \&$ Jolly Jacob ${ }^{2}$ \\ ${ }^{1}$ SM CSI Medical College, Karakonam, Trivandrum, Kerala, India \\ ${ }^{2}$ College of Arts \& Science, Abu Dhabi University, Abu Dhabi, UAE \\ Correspondence: Jolly Jacob, Department of Applied Science \& Mathematics, College of Arts \& Science, Abu \\ Dhabi University, PO Box 59911, Abu Dhabi, UAE. Tel: 971-501-5808. E-mail:jolly.jacob@adu.ac.ae
}

\author{
Received: February 12, 2018 Accepted: May 28, 2018 Online Published: June 11, 2018 \\ doi:10.5539/gjhs.v10n7p166 URL: https://doi.org/10.5539/gjhs.v10n6p166
}

\begin{abstract}
Herniorrhaphy or Hernioplasty is the surgical treatment for hernia. This surgical procedure is mainly done using local or general anesthesia with laparoscope or conventional incision. Laparoscopic hernioplasty is the best suited laparoscopic technique for almost all the abdominal hernias. This technique has gained its approval in recent treatment and is being widely used. Despite the fact that it is for the most part of safe operation, postoperative complications are found to be less. The recovery time after the surgery is found to be 1 to 2 weeks. Single port laparoscopy is the marginally invasive surgical process where the surgery takes place by a single entry point mainly the umbilicus. This single port technique leaves only a single scar. Multiport laparoscopic technique is the traditional technique where it uses many entry points for operation. Thus the single port laparoscopic technique consists of many advantages like faster recovery time, less blood loss, less post-operative pain etc. This study systematically reviewed the existing literatures for comparing the single site over the multiport hernia repair. The outcomes like hospital stay, operative time, complications and blood loss are reviewed. The remedial advantages in the general management of hernia are reviewed in detail. This review concludes that the single port laparoscopic hernioplasty is the most advantaged technique than the multiport.
\end{abstract}

Keywords: laparoscopic hernioplasty, Multi-port laparoscopy, Single port laparoscopy

\section{Introduction}

In the recent era of modern technology and invention, the slightly invasive surgical method is the standard procedure for numerous surgical procedures. The efficacy and safety of a laparoscopic technique over the open surgery has been recognized well during the previous few decades. This is connected with a decrease in postoperative pain, reduced hospital stay and an early return to work. Laparoscopic hernia repair is same as that of other laparoscopic procedural techniques. Laparoscopic surgery is one of the most important surgical advances in the field of medicine. Laparoscopic hernia repair is a comparatively new surgical procedure for fixing tears in the abdominal wall by means of small incisions, a patch and special cameras for observing interior body parts (Mishra, 2013).

Inguinal Hernia Repair (IHR) is the most recurrent elective surgery performed in the Europe and United States, although when comparing the rate of surgery performed for treating $\mathrm{IH}$, there is excessive variety among various populations (Mizrahi \& Parker, 2012). For example, IHR is performed in 10 per 10000 people in the United Kingdom, while the rate is 28 per 10000 people in the United States. There are many possible explanations for this observable fact, containing different primary care management, costs, and insurance policies. Similar to other surgery, elective IHR has its share of difficulties. Infection at the surgical site, urinary retention, hematoma and other short-term illnesses are well identified, as are long-term difficulties comprising neuralgia, long-term groin pain and recurrence of $\mathrm{IH}$. Yet, delaying the operation may carry a risk of severe IH and strangulation of visceral organ with extra risks of perforation, gangrene and infection of the peritoneal cavity. Thus, operations in the emergency situation for incarcerated IH have greater mortality rates and morbidity.

Laparoscopic Inguinal Hernia Repair (LIHR) in kids has become an alternate to the open practice. It is attaining popularity with more and more studies supporting its possibility, safety, and effectiveness (Shalaby et al., 2014). However, the more importance has been on the advancement of minimal invasive procedures like single-incision 
laparoscopic surgery. The single-incision strategy gives a less obtrusive option to the conventional laparoscopic surgery, requiring just a single incision inside the umbilical folds as opposed to three to five cuts in traditional multiport-laparoscopic surgery. The accessibility of various specific ports has helped the improvement of single-incision laparoscopic surgery and prompted to its far reaching use. The effective utilization of single-incision laparoscopic surgery has been accounted for various surgical methods, and offers a few potential advantages versus routine laparoscopic surgery, including minimal pain, less time to recuperation and enhanced cosmesis. It has been suggested that the single port laparoscopy is efficient over the multi-port laparoscopy in terms of complications, rate of conversion to open procedure and period of stay in hospital.

This study aims for the systematic review of the single port and multiport laparoscopic hernioplasty. Laparoscopic hernia repair is dissimilar from open surgery like a laparoscopic repair needs numerous small incisions rather than a single larger cut. These incisions are more in the multi-port laparoscopic technique, so in the modern single port laparoscopic technique only one incision is made and only one scar is produced. If hernias are on either side, both hernias could be treated at the same time without the necessity for a second large incision. Laparoscopic surgery permits the surgeon for examining both groin areas and each site of hernias for defects. This study also reviews the complications of the laparoscopic technique, comparison of the single port and multi-port technique and the hospital stay time etc.

\section{Laparoscopic Hernioplasty}

Ashfaq et al., (2014) stated that laparoscopic inguinal hernia repair is related with decreased post-operative pain and prior return to regular work in men. Still, the laparoscopic hernia repair role in females is not well described. The author reviewed the consequences of the laparoscopic surgery against open repair of inguinal hernias in women and discussed the patients' thoughts when selecting the approach. A surveying chart review of each consecutive patients experiencing inguinal hernia repair from the year 2005 to 2009 at a single organization was accompanied. Presentation features and consequence measures containing recurrence rates, post-operative pain and problems were compared in women undertaking laparoscopic versus open hernia repair. Laparoscopic inguinal hernia repair is related with lessened post- operative pain and prior come back to work in men. However, the part of laparoscopic hernia repair in women is not studied in detailed. In this study, the author has reviewed the results of the laparoscopic versus open repair of inguinal hernias in women and to examine patients' considerations while picking the approach. A review outline audit of every patient experiencing inguinal hernia repair from January 2005 to December 2009. Introduction attributes and result measures including repeat rates, post-operative pain and inconveniences were looked at in women experiencing laparoscopic versus open hernia repair. There was no difference of hernia recurrence, post-agent neuralgia, seroma/hematoma development or urinary retention between the two methodologies. A more patients with bilateral hernias had a laparoscopic approach instead of an open system. It was concluded that laparoscopic herniorrhaphy is as safe and effectual as open repair in women and is considered when the diagnosis is being referred to, for bilateral hernias management or while associative abdominal pathology is addressed.

Scarless surgery is known as the Holy Grail of surgery and the very raison d'etre of Minimal Access Surgery was the lessening of marks and thus pain and distress of the patients. The research by Muhe and Mouret in the late 80s, tiled the way for typical laparoscopic strategies and it quickly became the strategy for decision for many intra-abdominal methods. Single-incision laparoscopic surgery is an extremely exciting new methodology in the field of minimal access surgery which works for further decreasing the scars of typical laparoscopy and en route for scarless surgery. Natural orifice translumenal endoscopic surgery (NOTES) was produced for scarless surgery, yet did not increase popularity because of a diversity of reasons. NOTES, a term created by an association in the year 2005 (Rao et al., 2011). NOTES remain a research method with only a little clinical case has been described. The lack of success of NOTES appears to have urged on the interest in single-incision laparoscopy as an extremely doable technique in the present with least visible scarring, rendering a 'scarless' effect. Laparo-Endoscopic Single-site Surgery (LESS) is invented by a multidisciplinary association in the year 2008 for single-incision laparoscopic surgery. These are corresponding innovations with similar complications of access, absence of triangulation and lack of equipment as of date. LESS appears to offer an advantage to doctors with its well-known field of view and instruments similar to those utilized in conventional laparoscopy. LESS remains an advancing distinct technique utilized effectively in many a centre, however with a substantial way to go earlier it becomes mainstream. It presently stands among ordinary laparoscopy and NOTES in the armamentarium of slight access operation. The development of LESS is outlined giving an overview of all the techniques and devices available and likely to be available in the future.

Laparoscopic repairs, in any case, are noted to have lower rates of pain and postoperative numbness and to permit 
a quicker recovery to typical every day exercises when compared to open operations (Bittner et al., 2011). Laparoscopic hernioplasty can be gained by means of two different spaces. The Total Extra Peritoneal (TEP) approach takes into account repair of the hernia through the preperitoneal space without infringement of the peritoneum. By complexity, the Trans-Abdominal Preperitoneal Polypropylene (TAPP) repair requires passage through the stomach divider and repair through the peritoneal opening. Generally, these methodologies are expert with the utilization of three laparoscopic ports put in the umbilicus and the lower abdomen. More recently, specialists have reported effective method for inguinal hernia repairs utilizing Single-Incision Laparoscopic Surgery (SILS).

\section{Single Port Laparoscopic Hernioplasty}

Koca et al., (2015) reported Single incision laparoscopic (SIL) that attempted to advance laparoscopy with the point of speedier recuperation, less and increase the patient satisfaction. By decreasing trauma in the abdominal wall, SIL possibly offers preferred results over even traditional laparoscopic herniorrhaphy. Notwithstanding, SIL is still not an entrenched strategy and not broadly practiced. SIL is related with a few ergonomic difficulties contrasted and standard multi-port laparoscopy because of the treatment of straight instruments in parallel with the camera. The single incision diminishes the scope of development for both the surgeon and assistant; this has been related with expanded levels of surgeon exhaustion and disappointment

SPA (single-port access), SLaPP (single laparoscopic port procedure), SILS (single-incision laparoscopic surgery), OPUS (one-port umbilical surgery), SIMPLE (single-incision multiport laparo endoscopic surgery), NOTUS (natural orifice transumbilical surgery) and E-NOTES (embryonic natural orifice transumbilical endoscopic surgery, as the umbilicus is an embryonic structure) are other techniques used in the laparoscopy. There was a necessity for unifying these surgeries under a single terminology, so that it would be at ease for documenting new developments and guide this emerging technique (Rao et al., 2011). A multidisciplinary association of surgeons met at the Cleveland Clinic in July 2008 (LESSCAR- Laparo-Endoscopic Single Site Surgery Consortium for Assessment and Research), which brought out a white paper on this subject. They recommended the name of LESS Surgery for all such techniques which utilized a particular site for access. The association also recommended a normalization to report these surgeries as follows: "To obviously and fully convey all technical details, a 'compulsory descriptive second line' in all technical publications, which offers all relevant data at the very outset, for example: length and location of incision (abdominal [umbilical or extraumbilical], thoracic, or pelvic); method (transperitoneal, retroperitoneal, percutaneous intraluminal, transluminal); number/type of ports utilized; laparoscopic, endoscopic or robotic; type of optics utilized (rigid, flexible, coaxial cable, chip on tip, etc); type of instruments utilized (straight, curved, articulating or malleable); and whether any ancilliary 2-mm needlescopic equipment or extra ports employed." Similar to NOSCAR, the mandate for LESSCAR included creating a multidisciplinary group, solicit funding, establishing a registry and database of procedures, encouraging and managing LESS research and cooperating with recognized professional organizations for facilitating LESS presentations at their meetings, among other things. LESSCAR membership was kept inclusive, but insisted on IRB approval to carry out LESS research.

Single-Incision Laparoscopic Surgery (SILS) characterizes an exclusive twist in slightly invasive surgery. This new surgical technique was born out of the mission for scarless, extremely cosmetic surgery (Agaba et al., 2014). The main benefit of SILS appears to be cosmetic related; the umbilicus is the desired incision site since the scars may be easily concealed. Other reported advantages are better postoperative pain and a faster return to normal actions of daily living. The concept of a single-incision approach has been adopted for various surgical techniques ranging from sleeve gastrostomy, colectomy, and adrenalectomy to Nissen fundoplication. Since SILS becomes more extensively adopted, the incidence of Port-Site Hernias (PSHs) becomes a significant consideration in the whole risk-benefit discussion with the patient.

\section{Conventional Multi-Port Laparoscopic Hernioplasty}

The first principal laparoscopic inguinal hernia repair was performed about two decades ago, single incision laparoscopic surgery is set to reform insignificantly intrusive surgery. Notwithstanding, the loss of triangulation must be over-preceded so that the strategy can be promoted. Tran, (2011) reported on initial 100 laparoscopic add up to extraperitoneal hernia repairs utilizing a single incision point. The review partner encompassed 68 patients with a mean age of 44 (territory, 18 to 83 ): 36 unilateral and 32 bilateral hernias. Twelve patients also experienced umbilical hernia repair with the Ventralex fix needing no extra incision. A $2.5 \mathrm{~cm}$ to $3 \mathrm{~cm}$ crescentic incision inside the bounds of the umbilicus was performed. Standard analyzing instruments and 52-cm/5.5-mm/300 laparoscope were utilized. Operation times were 50 minutes for one-sided and 80 minutes for respective. There was one change to ordinary 3-port laparoscopic repair and none to open surgery. Outpatient surgery was accomplished on the 
whole (with the exemption of one). Pain relieving requirements were insignificant: 8 Dextropropoxyphene tablets (extend 0 to 20). It had no postoperative or intraoperative complexities with a high patient fulfillment score. Single-incision laparoscopic hernia repair is sheltered and effective just by changing dismemberment methods. Tantamount achievement can be acquired while refuting the risk of bowl and vascular wounds from sharp trocars and accomplishing enhanced restorative outcomes.

Outaggarts et al., (2015) have suggested that Port site metastases have been accounted for with laparoscopic surgery. The instrument of activity is not known. Hypotheses integrate tracking of tumour, pneumoperitoneum, spillage and immune factors. The author has described an instance of aggressive port site metastases and intra-stomach re-occurrence after a simple laparoscopic hysterectomy for a grade 2, unimportantly intrusive en-dometrioid adenocarcinoma of the uterus and the works on port site metastases in gynecological tumor was also reviewed. Port site metastases have two unmistakable introductions. In the main example, the metastases are confined to the laparoscopic port locales. In the second example, port site metastases are related with across the board intra-stomach repeat. At the end of the study it was concluded that Port site metastases are uncommon however happen with laparoscopic surgery. More consideration should be given to surgical strategy including the utilization of example packs to separate tissue and prevent spillage is to be performed. Information registries must be originated for tracking the rate and consequences of port site metastases.

Trocar site incisional hernia is most extensively recognized in laparoscopic surgery. In spite of the fact that this complexity can bring about morbidity, it is often underdiagnosed. Till date, the commonness of TSIH was accepted to go from $1.50 \%$ to $1.80 \%$, however it is normally accepted that without medium-term to long term follow up, and most cases will stay undiscovered. Trocar site incisional hernia has attempted to be kept away from or limited and the effect of Trocar site incisional hernia and its causal components to be determined in forthcoming studies. Distinguishing which patients will be at harm for Trocar site incisional hernia could be of significance to build up preventive measures or a follow-up timetable. Be that as it may, to date, there have been lacking planned arrangement with a long term follow-up to permit the effect of this entanglement to be broke down. The points of the present review were to assess the predominance of Trocar site incisional hernia and to examine the impact of a few risk factors for this complexity in a future series (Comajuncosas et al., 2014). From the year 2007 to 2008, a potential observational review with 3 years of continuation was performed containing every consecutive patient experienced elective laparoscopic. A multivariate examination was performed to recognize chance elements for Trocar site incisional hernia. Umbilical Trocar site incisional hernia is profoundly common. This review recognized a few factors that could be helpful to present preventive measures in high-risk patients.

\section{Post Operation Complications}

Witt et al., (2006) reported that Inguinal Hernia is a common condition, particularly in men; showing up in all age bunches with pinnacle occurrence in the infant, younger and also in grown up population. A National Health Survey on Hernia, led in 1960, established that hernias happen at a rate of 15 for every 1000 populace. Surgical repair of inguinal hernias speaks to an expansive segment of medicinal services exertion with around 700000 hernia surgeries played out every year in the United States. Hernias and hernia repair influence the quality of life of the patient and may substantially affect casual parental figures, particularly considering that a hefty portion of these patients are released an indistinguishable day from their surgery and quite a bit of their recuperation at home. In any case, no past work has analyzed the effect of this condition and the type of surgical repair. In this study, the author has collected information from a Veterans Affairs (VA) Cooperative Study to inspect the effect of hernia and hernia repair on parental figure trouble crosswise over time from preoperative estimation at 2 weeks and at 3 months post-operatively.

Acute portomesenteric venous thrombosis is an unusual yet life-threatening obstacle of laparoscopic surgical procedure (Sivasambu et al., 2015). Early diagnosis and treatment are fundamental to counteract life- threatening complications, for example, mesenteric ischemia and localized necrosis. A 51-year-old woman had laparoscopic small bowl resection and essential anastomosis with ventral hernia repair 4 weeks prior for fractional small bowel obstruction. The postoperative period was ordinary and the patient was sent home. Four weeks after surgery the patient had developed watery the runs and summed up stomach torment for four-day span. A figured tomography of the stomach area uncovered portomesenteric venous thrombosis despite the fact that a processed tomography of mid-region before surgery 4 weeks back did not determine any portomesenteric venous thrombosis. The author has reported that detailing an instance of intense portomesenteric venous thrombosis as an inconvenience of laparoscopic surgery.

\section{Comparison of Single and Multi-Port Hernioplasty}

SILS is an emerging field and the specifically designed ports essential for SILS are expensive, making this 
procedure too expensive to many. For overcoming this drawback, the usage of conventional affordable devices for SILS was fortified. The case series of SILS is presented with conventional apparatuses in a tertiary care centre (Akshay and Sameer, 2016). This is a single centre pilot study of 30 consecutive cases operated by SILS using conventional laparoscopic instruments. Effects measured were operative time, post-operative pain using Visual Analogue Scale (VAS), recommencement of oral diet, period of stay in the hospital, wound cosmesis and impediments. 21 women and 9 men with the average age $35.05 \pm 12.06$ years were operated by SILS technique. 20 Single Incision Laparoscopic Cholecystectomies (SILC), 7 Single Incision Laparoscopic Appendectomies (SILA) and 3 Single Incision Diagnostic Laparoscopies (SIDL) were performed by average operative time of 92 minutes, 47 minutes and 53 minutes individually. The entire surgeries were done successfully deprived of conversion to conservative laparoscopy or open technique. Many patients were given oral feeds and discharged on the second postoperative day without any complications. Wound cosmesis was acceptable with an unobtrusive scar in all patients. Our early experience of utilizing conventional laparoscopic tools for SILS validates its feasibility and usefulness especially in resource challenged settings. The advantage of SILS is its reduced need of analgesics and better wound cosmesis, without significant post-operative complications.

Background suggestion in the literature concerning the potential of SILS inguinal hernioplasty presently is limited (Buckley et al., 2014). A retrospective assessment of SILS and traditional multiport laparoscopic (MP) inguinal hernia repair was done for assessing the safety and viability of the minimally invasive laparoscopic surgery. SILS inguinal hernioplasty is a nontoxic and feasible alternate to traditional MP inguinal hernia repair and could be performed effectively with similar operative periods, complication and conversion rates. Prospective trials are needed to approve equivalence in these areas and to perceive alterations in patient-centered consequences.

Table 1. Surgical techniques adopted in the enrolled study

\begin{tabular}{|c|c|c|c|c|c|}
\hline Author & Comparison & $\begin{array}{l}\text { Total No of } \\
\text { patients }\end{array}$ & $\begin{array}{l}\text { No of patients } \\
\text { compared }\end{array}$ & Result & Conclusion \\
\hline $\begin{array}{l}\text { Kim et al } \\
(2009)\end{array}$ & $\begin{array}{l}\text { Single-Port (SP) TEP } \\
\text { and Conventional } \\
\text { Laparoscopic (CL) } \\
\text { TEP }\end{array}$ & 99 men & $\begin{array}{l}50 \text { - SP TEP } \\
49 \text { - CL TEP }\end{array}$ & $\begin{array}{l}\text { postoperative pain less in } \\
\text { SP TEP than CL TEP }\end{array}$ & $\begin{array}{l}\text { SP } \quad \text { TEP } \\
\text { recommended }\end{array}$ \\
\hline $\begin{array}{l}\text { Zhan et } \\
\text { al (2014) }\end{array}$ & $\begin{array}{l}\text { SILA with } \\
\text { Conventional } \\
\text { Multiport } \\
\text { Laparoscopic } \\
\text { Appendectomy } \\
\text { (CMLA) }\end{array}$ & $\begin{array}{l}\text { Random } \\
1,216\end{array}$ & $\begin{array}{l}611 \text { - SILA } \\
605 \text { - CMLA }\end{array}$ & $\begin{array}{l}\text { practical strain, continued } \\
\text { routine period, extent of } \\
\text { infirmary stay is less }\end{array}$ & $\begin{array}{l}\text { postoperative } \\
\text { discomfort in SILA is } \\
\text { less than CMLA }\end{array}$ \\
\hline $\begin{array}{l}\text { Cugura } \\
\text { et al } \\
(2012)\end{array}$ & $\begin{array}{l}\text { LESS-TEP with } \\
\text { LAP-TEP }\end{array}$ & 98 & $\begin{array}{l}25 \text { LESS-TEP } \\
29 \text { LAP-TEP } \\
44 \\
\text { conservations }\end{array}$ & $\begin{array}{l}\text { Within } 72 \text { hours most } \\
\text { patients are discharged in } \\
\text { both groups. }\end{array}$ & $\begin{array}{lr}\text { LESS-TEP } & \text { is a } \\
\text { harmless } & \text { possible } \\
\text { technique } & \text { equivalent } \\
\text { to } & \text { predictable } \\
\text { LAP-TEP } & \end{array}$ \\
\hline $\begin{array}{l}\text { Lo et al } \\
\text { (2016) }\end{array}$ & $\begin{array}{l}\text { LESS-TEP with } \\
\text { MP-TEP }\end{array}$ & 1109 & $\begin{array}{l}595 \\
\text { LESS-TEP } \\
514 \text { MP-TEP }\end{array}$ & $\begin{array}{l}\text { LESS-TEP } \\
\text { expressively took } \\
\text { active period than the } \\
\text { MP-TEP in unilateral hernia } \\
\text { repair. }\end{array}$ & $\begin{array}{l}\text { LESS -TEP is } \\
\text { different to MP-TEP. }\end{array}$ \\
\hline $\begin{array}{l}\text { Tsai et al } \\
\text { (2013) }\end{array}$ & LESS with CL-TEP & 100 & $\begin{array}{l}\text { LESS TEP -50 } \\
\text { CL TEP -50 }\end{array}$ & $\begin{array}{l}\text { Pain- relieving } \\
\text { requirements, complete } \\
\text { stress reactions, difficulties, } \\
\text { and postoperative recovery, } \\
\text { side to side mesh is gold } \\
\text { standard treatment }\end{array}$ & $\begin{array}{l}\text { LESS procedure takes } \\
\text { lead positively for } \\
\text { numerous operating } \\
\text { symptoms }\end{array}$ \\
\hline
\end{tabular}




\begin{tabular}{|c|c|c|c|c|c|}
\hline $\begin{array}{l}\text { Siddiqui et } \\
\text { al (2014) }\end{array}$ & $\begin{array}{l}\text { LESS } \\
\text { TEP } \\
\text { with } \\
\text { LAP } \\
\text { TEP }\end{array}$ & 325 & $\begin{array}{l}\text { LESS TEP } \\
128 \\
\text { LAP TEP } 159\end{array}$ & $\begin{array}{l}\text { No substantial differences } \\
\text { unilateral hernias or } \\
\text { bilateral repairs. No } \\
\text { significant differences in } \\
\text { hospital stay, intraoperative } \\
\text { complications or early } \\
\text { recurrence rates }\end{array}$ & $\begin{array}{l}\text { Slightly different process also } \\
\text { performs to be harmless and } \\
\text { effective. }\end{array}$ \\
\hline $\begin{array}{l}\text { Sajid et al } \\
(2016)\end{array}$ & $\begin{array}{l}\text { SILS } \\
\text { with } \\
\text { MILS }\end{array}$ & 1651 & Random & $\begin{array}{l}\text { Hospital stay, effective time } \\
\text { for unilateral and bilateral } \\
\text { hernias, post-operative sting } \\
\text { score, hernia repetition, } \\
\text { renovation are examined }\end{array}$ & $\begin{array}{l}\text { SILS is practicable, safe and } \\
\text { present in patient's disposal of } \\
\text { proficiency and properties. }\end{array}$ \\
\hline
\end{tabular}

\section{Limitations}

The consent is about the single port technique that is favorable stays disputable. As the ambulatory service becomes the standard of care, strategies are in evolution to enlarge the patient involvement in this setting. This practices the basis to evaluate prosthetic ventral hernia repair in the ambulatory situation (Downes, 2016). SILS procedure of ventral hernia repair utilizing the Stryker Ideal-eyes articulating laparoscope and standard laparoscopic devices in the day-case setting is reported. Three cases of ventral hernias (one primary and two incisional) were described. All were done utilizing single port methods. They were completed in the ambulatory setting and need no admission. Single incision laparoscopic repair of primary and incisional ventral hernias was done effectively in all cases lacking conversion to standard laparoscopic technique. The operative time is in the range of $66 \mathrm{~min}$ (39-95 min). No intra- or postoperative difficulties were documented. No incidents of extended postoperative pain were described. The literature is examined and subsequently discussed the viability of ambulatory single port ventral hernia repair. SILS prosthetic repair of primary and incisional ventral hernia is simply achievable. In our series, SILS ventral hernia repair seems to be safe and operative. It might decline parietal trauma augmentingits usage in the ambulatory setting. Technology will remain to improve the wide applicability of this method. Greater randomized trial studies are necessary for determining the rates of port-site incision alhernia compared with multiport laparoscopy.

\section{Conclusion}

This review concludes that laparoscopic hernioplasty is the safe technique, and can give less postoperative morbidity in experienced hands, as open herniorrhaphy. Single port laparoscopic hernioplasty has the greater advantage than the traditional multi-port laparoscopic hernioplasty. The traditional is not widely done in recent times. Laparoscopic hernioplasty is a valuable strategy that can decrease hospital stay and complications. Moreover, the patients can proceed with their normal activities after their hospital stay. The surgical morbidity and the efficacy were proved to be higher in the laparoscopic hernioplasty. LESS-TEP had greater surgical efficacy, conversion rate and complication rate in the short-term follow-up. These results suggested that LESS-TEP can be a feasible alternative to MP-TEP in all the patients.

\section{Competing Interests Statement}

The authors declare that there are no competing or potential conflicts of interest.

\section{References}

Agaba, E. A., Rainville, H., Ikedilo, O., \& Vemulapali, P. (2014). Incidence of port-site incisional hernia after $\begin{array}{lllll}\text { single-incision } & \text { laparoscopic } & \text { surgery. } & J S L S, & 18(2),\end{array}$ https://doi.org/10.4293/108680813X13693422518317

Akshay. K and Sameer. R (2016). Single Incision Multiport Laparoscopic Surgery (SILS) with Conventional Instruments: A Single Centre Experience. IOSR Journal of Dental and Medical Sciences, 15(7), 112-115.

Ashfaq, A., McGhan, L. J., Chapital, A. B., Harold, K. L., \& Johnson, D. J. (2014). Inguinal hernia repair in women: is the laparoscopic approach superior?. Hernia, 18(3), 369-373. https://doi.org/10.1007/s10029-013-1126-3

Bittner, R., Arregui, M. E., Bisgaard, T., Dudai, M., Ferzli, G. S., Fitzgibbons, R. J., ... \& Kukleta, J. (2011). Guidelines for laparoscopic (TAPP) and endoscopic (TEP) treatment of inguinal hernia [International Endohernia Society (IEHS)]. Surgical endoscopy, 25(9), 2773. https://doi.org/10.1007/s00464-011-1799-6 
Buckley, F. P., Vassaur, H., Monsivais, S., Sharp, N. E., Jupiter, D., Watson, R., \& Eckford, J. (2014). Comparison of outcomes for single-incision laparoscopic inguinal hernioplasty and traditional three-port laparoscopic hernioplasty at a single institution. Surgical endoscopy, 28(1), 30-35. https://doi.org/10.1007/s00464-013-3145-7

Comajuncosas, J., Hermoso, J., Gris, P., Jimeno, J., Orbeal, R., Vallverdú, H., ... \& Parés, D. (2014). Risk factors for umbilical trocar site incisional hernia in laparoscopic cholecystectomy: a prospective 3-year follow-up study. The American Journal of Surgery, 207(1), 1-6. https://doi.org/10.1016/j.amjsurg.2013.05.010

Cugura, J. F., Kirac, I., Kulis, T., Sremac, M., Ledinsky, M., \& Beslin, M. B. (2012). Comparison of single incision laparoscopic totally extraperitoneal and laparoscopic totally extraperitoneal inguinal hernia repair: initial experience. Journal of endourology, 26(1), 63-66. https://doi.org/10.1089/end.2011.0352

Downes, R. O. (2016). Single incision laparoscopic primary and incisional ventral hernia repair as the standard of care in the ambulatory setting; Does less equal better outcomes; Case series and literature review. International Journal of Surgery Case Reports, 26, 73-76. https://doi.org/10.1016/j.ijscr.2016.07.015

Kim, T. J., Lee, Y. Y., Kim, M. J., Kim, C. J., Kang, H., Choi, C. H., ... \& Bae, D. S. (2009). Single port access laparoscopic adnexal surgery. Journal of minimally invasive gynecology, 16(5), 612-615. https://doi.org/10.1016/j.jmig.2009.06.011

Koca, D., Yıldız, S., Soyupek, F., Günyeli, İ., Erdemoglu, E., Soyupek, S., \& Erdemoglu, E. (2015). Physical and mental workload in single-incision laparoscopic surgery and conventional laparoscopy. Surgical innovation, 22(3), 294-302. https://doi.org/10.1177/1553350614556363

Lo, C. W., Shei-Dei Yang, S., Tsai, Y. C., Hsieh, C. H., \& Chang, S. J. (2016). Comparison of laparoendoscopic single-site versus conventional multiple-port laparoscopic hernioplasty : a systemic review and meta-analysis. Hernia, 20(1), 21-32. https://doi.org/10.1007/s10029-015-1443-9

Mishra, R. K. (2013). Laparoscopic Hernia Repair. JP Medical Ltd. https://doi.org/10.5005/jp/books/11876

Mizrahi, H., \& Parker, M. C. (2012). Management of asymptomatic inguinal hernia: a systematic review of the evidence. Archives of Surgery, 147(3), 277-281. https://doi.org/10.1001/archsurg.2011.914

Outaggarts, Z., Johnstone, S., \& Goodman, A. (2015). Port-Site Metastasis after Laparoscopic Surgery with Rapid Second Recurrence in Early Stage Endometrial Carcinoma: A Case Report and Review of the Literature. Open Journal of Obstetrics and Gynecology, 5(06), 324. https://doi.org/10.4236/ojog.2015.56047

Rao, P. P., Rao, P. P., \& Bhagwat, S. (2011). Single-incision laparoscopic surgery-current status and controversies. Journal of minimal access surgery, 7(1), 6 .

Sajid, M. S., Khawaja, A. H., Sayegh, M., \& Baig, M. K. (2016). A systematic review comparing single-incision versus multi-incision laparoscopic surgery for inguinal hernia repair with mesh. International Journal of Surgery, 29, 25-35. https://doi.org/10.1016/j.ijsu.2016.02.088

Shalaby, R., Ismail, M., Samaha, A., Yehya, A., Ibrahem, R., Gouda, S., ... \& Alsamahy, O. (2014). Laparoscopic inguinal hernia repair; experience with 874 children. Journal of pediatric surgery, 49(3), 460-464. https://doi.org/10.1016/j.jpedsurg.2013.10.019

Siddiqui, M. R., Kovzel, M., Brennan, S. J., Priest, O. H., Preston, S. R., \& Soon, Y. (2014). The role of the laparoendoscopic single site totally extraperitoneal approach to inguinal hernia repairs: a review and meta-analysis of the literature. Canadian Journal of Surgery, 57(2), 116. https://doi.org/10.1503/cjs.010612

Sivasambu, B., Yogarajah, M., \& Wilson, T. (2015). Acute Portomesenteric Venous Thrombosis following Laparoscopic Small Bowel Resection and Ventral Hernia Repair. Case reports in gastrointestinal medicine. https://doi.org/10.1155/2015/851852

Tran, H., Turingan, I., \& Tran, M. (2013). Single-incision laparoscopic ventral hernia repair with suprapubic incision. JSLS: Journal of the Society of Laparoendoscopic Surgeons, 17(2), 316. https://doi.org/10.4293/108680813X13654754534431

Tsai, Y. C., Ho, C. H., Tai, H. C., Chung, S. D., \& Chueh, S. C. (2013). Laparoendoscopic single-site versus conventional laparoscopic total extraperitoneal hernia repair: a prospective randomized clinical trial. Surgical endoscopy, 27(12), 4684-4692. https://doi.org/10.1007/s00464-013-3116-z

Witt, W. P., Gibbs, J., Wang, J., Giobbie-Hurder, A., Edelman, P., McCarthy, M., \& Neumayer, L. (2006). Impact of inguinal hernia repair on family and other informal caregivers. Archives of Surgery, 141(9), 925-930. 
https://doi.org/10.1001/archsurg.141.9.925

Zhang, Y., Zhou, H., Chai, Y., Cao, C., Jin, K., \& Hu, Z. (2014). Laparoscopic versus open incisional and ventral hernia repair: a systematic review and meta-analysis. World journal of surgery, 38(9), 2233-2240. https://doi.org/10.1007/s00268-014-2578-z

\section{Copyrights}

Copyright for this article is retained by the author(s), with first publication rights granted to the journal.

This is an open-access article distributed under the terms and conditions of the Creative Commons Attribution license (http://creativecommons.org/licenses/by/4.0/). 